\title{
O Paradoxo da Origem do Poder Político EM ROUSSEAU
}

\author{
THE PARADOX OF THE ORIGIN OF POLITICAL POWER \\ IN ROUSSEAU
}

Ligia Pavan Baptista ${ }^{1}$

RESUMO: O presente artigo pretende abordar a forma original com a qual Rousseau focaliza a questáo da origem do poder político, tema que é central na teoria política moderna. Em sua obra Do Contrato Social, o autor examina as razốes, aparentemente paradoxais, pelas quais alguém, nascido livre, se escravizaria voluntariamente, obedecendo a outro e não a si próprio. Distanciando-se da influência de Hobbes e Locke, o autor apresenta a tese do contrato social, fundado no conceito de vontade geral, como o único meio pelo qual o indivíduo se realizaria enquanto ser humano. Ao assumir sua condição de cidadão, unindo-se a todos em vista do bem comum e não obedecendo a ninguém a não ser a si próprio, o mesmo adquire tanto a igualdade quanto a liberdade civil, condiçōes sem as quais deixaria de existir. Somente dessa forma, cada cidadáo, exercendo seus direitos e deveres, seria detentor de parcela da soberania, enquanto membro da vontade geral, no direito de legislar.

PALAVRAS-CHAVE: Rousseau. Contrato Social. Vontade Geral. Liberdade. Igualdade.

A modernidade, na história da teoria política, eleva a questão da origem do poder político como prioritária. A partir do século XVII, o poder político é caracterizado tanto pelo seu caráter laico, em relaçấo às teorias do direito divino dos reis explicitadas pela filosofia cristâ, quanto por seu caráter artificial, contrariando as teorias patriarcalistas expostas por Jean Bodin (1530-1596) e Robert Filmer (1588-1653). Respectivamente, os autores de O Patriarca e os Seis Livros da República propunham estabelecer uma origem natural ao poder político, com base na analogia entre o poder do monarca e o poder paterno, ou seja, com base numa suposta analogia entre a família e o Estado. A tese de uma suposta analogia entre as formas de poder privado e aquela do poder público, levando em conta o caráter supostamente natural de ambas, se torna inaceitável, definitivamente, como paradigma da análise

\footnotetext{
${ }^{1}$ Doutora em Filosofia (FFCH/USP). Professora da Universidade de Brasília. E-mail: ligiabap@unb.br - http://dx.doi.org/10.1590/S0101-317320150004000010
} 
política na modernidade, como exposto, de forma contundente, pelos contratualistas ingleses Thomas Hobbes (1588-1679) e John Locke (16321704). Sobretudo expresso no pensamento contratualista/iluminista do século XVIII, no qual Rousseau pode ser incluído, o pensamento político moderno, após análise aprofundada da natureza humana, sem a qual suas premissas não se sustentariam, se funda na constatação, até então inédita, de que todos os seres humanos nascem livres e iguais, ou seja, que assim devem ser considerados, ainda que sejam evidentes as diferenças, seja em capacidades físicas, seja em mentais. A premissa da igualdade natural dos homens é tratada por Hobbes no capítulo XIII do Leviatã, onde o autor aborda a condição natural da humanidade na ausência de um poder comum:

A natureza fez os homens tăo iguais, quanto às faculdades de corpo e de espírito que, embora por vezes se encontre um homem manifestamente mais forte de corpo, ou de espírito mais vivo do que outro, mesmo assim, quando se considera tudo isso em conjunto, a diferença entre um e outro homem não é suficientemente considerável para que qualquer um possa com base nela reclamar qualquer benefício a que outro não possa também aspirar tal como ele. (HOBBES, 1988, p. 74).

Como consequência lógica de tal ponto de partida de análise política, definida por Hobbes não somente no Leviatã, mas igualmente em suas obras anteriores, Os Elementos do Direito e Do Cidadão, após longa e detalhada análise preliminar sobre a natureza humana, a origem do poder político não poderia estar fundada numa suposta origem divina ou natural. A artificialidade do poder político é a condição essencial para tornar possível a ciência política, pois podemos conhecer somente aquilo que foi por nós mesmos produzido ou criado.

Não havendo nenhuma forma de hierarquia inscrita na natureza, desde então, a origem contratual e, portanto, artificial, seria a única origem considerada legítima, não somente do poder político, mas de quaisquer formas de poder, até mesmo daquelas inscritas na esfera privada, tese por meio da qual os contratualistas entendem inclusive o pátrio poder e a escravidão como sendo consensuais e não naturais.

Músico genebrino de nascimento e, após sua morte, herói francês, Jean-Jacques Rousseau (1712-1778), compositor da ópera "O Adivinho da Aldeia", encenada em Fointainebleau em 1752, autor dos verbetes "música" e “economia política”, na Enciclopédia de Diderot, altera o rumo de seu próprio 
destino, do pensamento político e da história moderna, ao vencer o primeiro concurso promovido pela Academia de Dijon, revelando raro talento literário e retórico aliado ao conhecimento profundo das obras e dos autores que o precederam, e ainda ao rigor metodológico de quem pretende fazer ciência e não literatura ou história. Ao abordar o tema "Se o progresso das ciências e das artes contribuiu para o aprimoramento ou para a degeneração dos costumes", o autor defende a tese de que a modernidade traria consequências nocivas à moralidade, em seu Discurso sobre as Ciências e as Artes, publicado em 1750, também chamado de Primeiro Discurso.

Com o objetivo de concorrer ao segundo prêmio promovido pela Academia de Dijon, discorrendo sobre o tema "Se a desigualdade entre os homens está ou não inscrita na natureza", ao publicar, em 1755, o Discurso Sobre a Origem e os Fundamentos da Desigualdade entre os Homens", também chamado de Segundo Discurso, o autor expóe, do ponto de vista de uma história hipotética, o que teria sido, supostamente, a evolução antropológica da natureza humana, com base em relatos de viajantes que descreveram a condição dos povos selvagens na América, os quais inspiraram anteriormente a concepção do Estado de Natureza tanto em Hobbes quanto em Locke. Reforçando a perspectiva negativa já exposta no primeiro Discurso, Rousseau lamenta a transformação gradativa do homem selvagem, ou isolado, em homem civilizado, ou socializado. Considerando que a civilização corrompe o homem selvagem em todos os sentidos, o autor genebrino enfatiza que este perde, gradativamente, ao se relacionar com outros, deixar de ser nômade e criar instrumentos para se proteger, quer sua pureza original de sentimentos, quer as potencialidades de suas capacidades físicas, tal como ressalta Kuntz:

O Discurso sobre as ciências e as artes aparece, em primeiro lugar, como uma incrível rejeição de tudo quanto constitui o orgulho dos homens civilizados. E o Discurso sobre a desigualdade parece levar a algo mais extremo, com a valorização do estado selvagem e primitivo. (KUNTZ, 2012, p. 74-75).

Declarando-se feliz na condição de cidadão genebrino, fato que contrasta com o momento histórico testemunhado por Hobbes e Locke, diante das desordens sociais as quais culminaram na guerra civil inglesa, Rousseau, ainda que herde dos contratualistas britânicos a tese central da origem do poder político fundado em bases artificiais, se opóe claramente à tese hobbesiana que estabelece não só uma distinção, como uma oposição entre direito e dever, considerando o primeiro uma liberdade, e o segundo, uma obrigaçáo. Com 
a declarada intenção de se instruir nos assuntos da política, como um dever para melhor exercer seu direito enquanto cidadão, sua proposta de conciliação entre direitos e deveres é fundada no duplo papel que sua original concepção de cidadania implica:

Tendo nascido cidadáo de um Estado Livre e membro do soberano, embora fraca seja a influência que minha opiniáo possa ter nos negócios públicos, o direito de neles votar basta para impor o dever de instruirme ao seu respeito, sentindo-me feliz todas as vezes que medito sobre os governos, por sempre encontrar, em minhas cogitaçoes, motivos para amar o governo do meu país. (ROUSSEAU, 1999, p. 51-52).

Assim sendo, contrariando a tese hobbesiana segundo a qual direitos e deveres seriam termos opostos por designarem, respectivamente, liberdade e obrigação, Rousseau, assim como Locke, propóe conciliar ambos.

Examinar as razóes, aparentemente paradoxais, pelas quais alguém nascido livre se escravizaria, obedecendo a outro e não a si próprio, e ainda mais paradoxal, que tal escravidão, nesse caso, não seria forçada, mas voluntária, é a tarefa a que o autor se propóe solucionar. A resposta para essa questáo paradoxal se encontra na origem do poder político e na relação deste com a condição natural do homem de liberdade e de igualdade.

Kuntz ressalta que a teoria política apresentada por Rousseau utiliza linguagem de forte apelo retórico que, muitas vezes, pela qualidade literária, deixa em segundo plano o conteúdo exposto, sendo influenciada tanto por Maquiavel e Hobbes quanto por Locke, Montesquieu, Grotius e Pufendorf (KUNTZ, 2012, p. 11).

Ao criticar sobretudo a teoria contratualista de Hobbes, Rousseau propóe soluçôes originais, sobretudo em relação aos princípios da liberdade e da igualdade. $\mathrm{O}$ autor introduz o conceito de liberdade civil como uma resposta à teoria da representação política hobbesiana exposta de forma detalhada no capítulo XV do Leviatã - "Das pessoas e das coisas que podem ser personificadas" -, onde se apresenta uma analogia entre a representação política e a representação teatral. Nesse sentido, o conceito de vontade geral, condição de realizaçáo do contrato social, seria uma refutaçáo veemente ao conceito de pessoa artificial, por meio do qual Hobbes define o Leviatã, animal mitológico utilizado como sinônimo de Estado pelo autor, entendido como um representante (ator) daqueles que o instituíram (autores). 
Na visão de Hobbes, o Estado Político não poderia ser criado sem a transferência coletiva e simultânea de um direito. Definindo direito como uma liberdade, seria ela mesma o objeto da transferência a um representante comum, no ato do contrato. $\mathrm{Na}$ visão de Rousseau, não poderia haver transferência da liberdade, a não ser que aquele que a transfere faça parte, ainda que de uma pequena parcela, da soberania, para que tal direito possa ser transferido, em última instância, do indivíduo para ele mesmo, em seu duplo papel na esfera política, de cidadão e de parte da soberania.

Partilhando com os contratualistas ingleses Hobbes e Locke a tese de que o contrato é um artefato, enquanto produto da arte humana, e seria a única origem legítima do poder político, Rousseau afirma, no primeiro capítulo do livro I de sua obra Do Contrato Social: "A ordem social, porém, é um direito sagrado que serve de base a todos os outros. Tal direito, no entanto, não se origina da natureza: fundase, portanto, em convençóes" (ROUSSEAU, 1999, p. 53-54).

Tal conclusão só foi possível após o minucioso estudo da natureza humana que ele elabora, no Segundo Discurso, considerando este o mais necessário e até então o menos estudado assunto. É somente a partir de tal estudo preliminar que o autor inicia suas investigaçôes sobre a moral e a política destacadas em Do Contrato Social, com a focalização da questão paradoxal que irá desenvolver na obra: "O homem nasce livre, e por toda parte encontra-se a ferros. $\mathrm{O}$ que se crê senhor dos demais, não deixa de ser mais escravo do que eles. Como adveio tal mudança? Ignoro-o. Que poderá legitimá-la? Creio poder responder essa questão" (ROUSSEAU, 1999, p. 53).

Como salienta Kuntz, o paradoxo, que é mais evidente em Rousseau do que em outros autores, reside em conciliar liberdade e autoridade, ou seja, conciliar, sem contradiçóes, termos aparentemente tão opostos quanto liberdade e obediência, no sentido de sujeição:

Como conceber, no entanto, uma sociedade sem leis e sem autoridade? A conciliação da autoridade e da liberdade é talvez o maior paradoxo que a filosofia política deve resolver. E em nenhum outro autor esse paradoxo se mostra de modo táo claro e tấo forte quanto em Rousseau. (KUNTZ, 2012, p. 124).

O mesmo paradoxo inicial é expresso por Rousseau ainda da seguinte forma: "Encontrar uma forma de associação que defenda e proteja a pessoa e os bens de cada associado com toda a força comum, e pela qual cada um, 
unindo-se a todos, só obedece contudo a si mesmo, permanecendo assim tão livre quanto antes" (ROUSSEAU 1999, p. 69-70).

A concepção rousseauniana de liberdade está fundada no pensamento político de Locke. Ambos a consideram restrita, tanto no estado de natureza quanto no estado político, respectivamente, pelo direito natural (bom senso e capacidades individuais) e pelo direito civil (vontade geral). Os dois concebem ainda a liberdade como a essência na natureza humana. Ou seja, para eles, a liberdade seria um direito natural do qual, nem mesmo por consentimento próprio, o homem poderia abrir mão sem o risco de perder, ao mesmo tempo, sua própria vida e sua condição humana.

$\mathrm{Na}$ visão de Rousseau, o ato de alienar a própria liberdade é considerado como desprovido de qualquer sentido, isto é, um absurdo do ponto de vista lógico:

Renunciar à liberdade é renunciar à qualidade de homem, aos direitos da humanidade, e até aos próprios deveres. Não há recompensa possível para quem a tudo renuncia. Tal renúncia não se compadece com a natureza do homem, e destituir-se voluntariamente de toda e qualquer liberdade equivale a excluir a moralidade de suas ações. (ROUSSEAU, 1999, p. 62).

Tendo em vista manter a liberdade e a igualdade naturais, sem deixar de levar em conta a necessidade da criação do poder político, Rousseau introduz o conceito de vontade geral, condição imprescindível à realização do contrato social, pelo qual a liberdade seria alienada em favor de cada um que, pelo pacto fundador do poder político, a alienou. Em um primeiro momento, aliena-se a liberdade natural, enquanto parte contratante do pacto que funda o poder político, e, em um segundo momento, por meio do mesmo pacto e do conceito de vontade geral, aquele que a alienou adquire a liberdade civil.

$\mathrm{Na}$ visão de Hobbes, a igualdade natural teria o mesmo sentido que a liberdade natural. Dessa forma, declara o autor, o Estado Político náo poderia ser criado sem a transferência mútua de um direito (liberdade) e sem a quebra da igualdade natural, através da consolidação da relação hierárquica entre soberano/cidadâo. Portanto, seria imprescindível deixar a situação de guerra de todos contra todos, expressão de forte apelo retórico com a qual o autor define o Estado de Natureza, caracterizado pela igualdade e pela liberdade, e criar a ordem política, sem a qual a espécie humana seria extinta.

A proposta que Rousseau apresenta para solucionar o paradoxo, com o qual inicia suas investigaçóes sobre política, se funda no conceito de liberdade 
civil, definido como obedecer à lei que cada um, como parte da vontade geral, cria, sendo essa a liberdade civil, enquanto resposta à teoria da representaçáo política hobbesiana, a única e verdadeira liberdade concebida pelo autor genebrino com o pacto social estabelecido pela vontade geral.

Concluindo o capítulo IX do Livro I, Rousseau afirma, de modo semelhante, que a condiçấo de igualdade natural da humanidade deve ser reforçada pela lei civil, uma vez fixado o poder político:

Terminarei este capítulo e este livro por uma observação que deverá servir de base a todo o sistema social: o pacto fundamental, em lugar de destruir a igualdade natural, pelo contrário substitui por uma igualdade moral e legítima aquilo que a natureza poderia trazer de desigualdade física entre os homens, que, podendo ser desiguais na força ou no gênio, todos se tornam iguais por convenção e direito. (ROUSSEAU, 1999, p. 81).

Nesse sentido, contrariando frontalmente a teoria hobbesiana, Rousseau afirma que nada se perde, nada se aliena, nada se transfere, ao se fundar o Estado Político. Ao contrário, não somente a condição de liberdade, mas também a igualdade naturais, se podemos aqui considerá-las condiçóes distintas, seriam reforçadas por convenção e somente a partir de então é que o ser humano atingiria sua plena condição humana, ao se tornar livre no plano político. Nessa perspectiva, Kuntz enfatiza: "A teoria da vontade geral dá um novo sentido e uma nova expressão ao velho tema da sujeç̧áo à lei como condiçāoo de liberdade" (KUNTZ, 2012, p. 18).

Finalmente, conclui-se que, apesar das especificidades de cada autor já apontadas, o pensamento contratualista, centrado nas teorias de Hobbes, Locke e Rousseau, posteriormente assimiladas pelo pensamento político de Kant, no século XIX, tem como premissa inicial da análise política a análise preliminar da natureza humana, por meio da qual se pode concluir que a condição da natureza humana, na ausência de um poder comum, seria de igualdade e liberdade.

Em segundo lugar, que, sendo a condição de igualdade uma condição de ausência de qualquer forma de hierarquia, não haveria sujeição entre iguais e, como consequência lógica, todos seriam igualmente livres. Em terceiro, que os dois conceitos podem ser tomados como sinônimos, tendo, nos três autores, o mesmo sentido de ausência de sujeição e ainda que, a partir dessa constatação, a origem do poder político não poderia estar fundada na natureza. Em quarto, 
que não restariam outros meios a não ser as convençôes artificiais, entendidas, desde então, como a única origem legítima não somente do poder político, mas, igualmente, de quaisquer outras formas de poder, até mesmo daquelas da esfera privada, consideradas naturais. Todavia, é somente em Rousseau que os conceitos de liberdade e igualdade civil surgem como sendo, de fato, as verdadeiras e únicas liberdade e igualdade. Sendo assim, segundo a concepçáo original do autor, é somente no plano político que o ser humano se realizaria enquanto ser humano, pois seria somente aí que o mesmo poderia alcançar a condição de liberdade essencial para a realização de sua própria condição humana. É dessa forma que Rousseau apresenta a solução para a questão paradoxal com a qual inicia suas investigaçóes sobre política, como evidencia nas primeiras linhas Do Contrato Social, sem maiores pretensóes a náo ser a de melhor se instruir para poder melhor exercer sua cidadania em Genebra. Não imaginaria ele que suas palavras seriam utilizadas como instrumento de mobilização da opiniáo pública, para fomentar os ideais iluministas os quais inspiraram os revolucionários franceses, tornando universais, a partir de então, os princípios da liberdade e da igualdade.

BAPTISTA, Ligia Pavan. The paradox of the origin of political power in Rousseau. Trans/ Form/Ação, Marília, v. 38, p. 111-120, 2015. Edição Especial.

\begin{abstract}
The article aims at discussing the new approach proposed by Rousseau regarding the question of the origin of political power, which is a central aspect of modern political theory. In his masterpiece The Social Contract, the author analyzes the apparently paradoxical reasons why someone born free could become a slave by his own free will, and, as such, subject to the authority of one other than himself. Going beyond the influence of Hobbes and Locke, the author presents the thesis of the social contract, based on the concept of the general will and considered the only way through which man can realize the human condition. By achieving the condition of citizen, each one as his own master and uniting with all others and looking toward the common good, man can reach the necessary conditions for his own existence: the conditions of equality and liberty.
\end{abstract}

KEYWORDS: : Rousseau. Social Contract. General Will. Liberty. Equality.

\title{
REFERÊNCIAS
}

BAPTISTA, Ligia Pavan. Da criação ex-nihilo ao artefacto do Estado: a gênese do Estado em Hobbes. 1994. 147p. Dissertação (Mestrado) - Universidade de São Paulo, São Paulo, 1994. 
. A questão da paz na teoria politica de Hobbes. 2003. 189p. Tese (Doutorado) Universidade de São Paulo, São Paulo, 2003.

BOBBIO, Norberto. Dicionário de politica. Brasília: Editora Universidade de Brasília, 1992.

FONSECA JÚNIOR, Gelson. Prefácio. In: ROUSSEAU, Jean-Jacques. Rousseau e as relaçóes internacionais. São Paulo: Imprensa Oficial do Estado, 2003.

HOBBES, Thomas. Leviatã. Trad. João Paulo Monteiro e Maria Beatriz Nizza da Silva. 4. ed. São Paulo: Nova Cultural, 1988.

. Do cidadão. São Paulo: Martins Fontes, 1991.

KELSEN, H. Le Droit naturel. Paris: PUF, 1959.

KOYRÉ, Alexandre. Estudos de história do pensamento cientifico. Rio de Janeiro: Forense Universitária; Brasília: Editora da UnB, 1982.

KUNTZ, Rolf. Resenha de Rousseau e as relaçóes internacionais. Política Externa, São Paulo, v. 13, n. 2, set./nov. 2004.

. Fundamentos da teoria política de Rousseau. São Paulo: Barcarolla: FAPESP, 2012.

LAFER, Celso. Hobbes, o direito e o Estado moderno. São Paulo: Associação dos Advogados de São Paulo, 1980.

LOCKE, John. Segundo tratado do governo civil. São Paulo: Abril Cultural, 1978.

ROUSSEAU, Jean-Jacques. Discurso sobre a origem e os fundamentos da desigualdade entre os homens. São Paulo: Abril Cultural, 1978.

Do contrato social e ensaio sobre a origem das linguas. Trad. Lourdes Santos Machado. Introduções e notas de Paul Arbousse-Bastide e Lourival Gomes Machado. São Paulo: Nova Cultural, 1999.

SKINNER, Quentin R. D. The foundation of modern political thought. Cambridge: Cambridge University Press, 1978. 2v.

Recebido / Received: 15/04/2015

Aprovado / Approved: 24/06/2015 
BAPTISTA, L. P. 